\title{
Characterization of BTEX sources in a medium-size city by concentration statistical analysis and GIS technique
}

S. Capasso ${ }^{1,2}$, M. Monaco ${ }^{2}$, P. Iovino ${ }^{2}$, S. Salvestrini ${ }^{2}$

\& M. Vigliotti ${ }^{2}$

${ }^{I}$ Regional Centre of Competence AMRA, Italy

${ }^{2}$ Department of Environmental Science, Second University of Naples, Italy

\begin{abstract}
The concentrations of benzene, toluene, ethylbenzene and the isomeric xylenes (BTEX) were determined in the atmosphere of S. Maria Capua Vetere city, in sixteen sites, ten times per site, during 2006. This city is of medium size, with about 32,000 inhabitants and is located in Southern Italy. Passive adsorption samplers, followed by GC/MS analyses, were used for BTEX determinations. The 24-hour average BTEX concentrations showed a marked variability from site to site. In some streets the pollutant concentrations were above the limit values required by the European Union. These streets were characterised by relatively intense traffic, but are rather narrow and have high buildings on either side. In the entire city the main pollutant source was road traffic. Moreover, analyses of the correlation coefficients among the BTEX concentrations and GIS maps highlighted the contribution of stationary sources to toluene air concentration. Their contribution has been quantified.
\end{abstract}

Keywords: BTEX, GIS technique, GC/MS analyses, pollutant concentration, diffusive sampler.

\section{Introduction}

Aromatic hydrocarbons, in particular benzene, toluene, ethylbenzene and xylenes (BTEX) are among the main pollutants in urban areas [1] and their adverse effects on human health are well documented [2]. Several studies [3, 4] have shown that the highest contribution to BTEX in urban areas is from the vehicular traffic. In many cases, however, it has been observed that emission from 
stationery sources, for example evaporation of solvents in factories and of fuel in fuel stations, also plays a relevant role [5]. Aromatic compounds emitted from the exhaust pipe consist mainly of unburned aromatic fuel components [6]. However, in the air the content of benzene, in relation to other aromatic compounds, is significantly higher than its fuel percentage, because benzene is a partially oxidized product of other aromatic compounds [7]. As these hydrocarbons react in the mesosphere with different rate constants, their relative concentrations change with the time of permanence in air [1].

This paper reports an investigation on BTEX concentrations in S. Maria Capua Vetere, carried out with the aim to analyse the relative impact on pollution levels of the road traffic and of small factories located in the urban area or in the suburbs. S. Maria Capua Vetere is a medium-size city, about 32,000 inhabitants, 0.6 cars per inhabitant, and is located in Southern Italy: lat. $41^{\circ} 5^{\prime} \mathrm{N}$, long. $14^{\circ} 15^{\prime} \mathrm{S}$.

\section{Experimental}

\subsection{Sampling sites}

The location of sampling sites is indicated in Figure 1. The sampling was performed on weekdays from February to November 2006 except August, 1 or 2 samplings per month. The data collected on rainy days were not included. All sampling points were located along the streets of the city, about $5 \mathrm{~m}$ above the ground level and not in proximity of cross-roads.

\subsection{Analytical procedures}

The BTEX compounds (benzene, toluene, ethylbenzene, o-xylene and $(\mathrm{m}+\mathrm{p})$ xylene) were collected by Radiello ${ }^{\circledR}$ diffusive samplers, patented by Foundation Salvatore Maugeri (FSM). The exposition time for each monitoring campaign was 24 hours. The samplers consisted of a stainless steel net cylinder with a 100mesh-grid opening, packed with $530 \mathrm{mg}$ of activated charcoal. The analyses were carried on a Perkin Elmer GC-MS instrument, model Clarus 500 equipped with a thermal desorption instrument, model TurboMatrix ATD. A stream of helium of $80 \mathrm{~mL} \mathrm{~min}^{-1}$ at $320^{\circ} \mathrm{C}$ for 10 min was applied to the exposed cartridges to extract the analytes. These were condensed in a trap at $2^{\circ} \mathrm{C}$. Then the trap was heated at $290^{\circ} \mathrm{C}$ for $1 \mathrm{~min}$.

The column used was an Elite-5MS fused silica capillary, $30 \mathrm{~m} \mathrm{x} 0.25 \mathrm{~mm}$, $0.25 \mu \mathrm{m}$ film thickness (Perkin Elmer Instruments). The oven temperature program was $35^{\circ} \mathrm{C}$ for $5 \mathrm{~min}$, to $120^{\circ}$ at $8^{\circ} \mathrm{C} / \mathrm{min}$ and to $200^{\circ} \mathrm{C}$ at $15^{\circ} \mathrm{C} / \mathrm{min}$. The

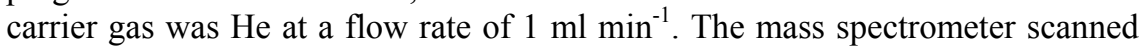
from 35 to 300 a.m.u. every $0.1 \mathrm{~s}$, in the electronic impact $(70 \mathrm{eV})$ mode. The ion source temperature was $180^{\circ} \mathrm{C}$ and the multiplier voltage $350 \mathrm{~V}$. 


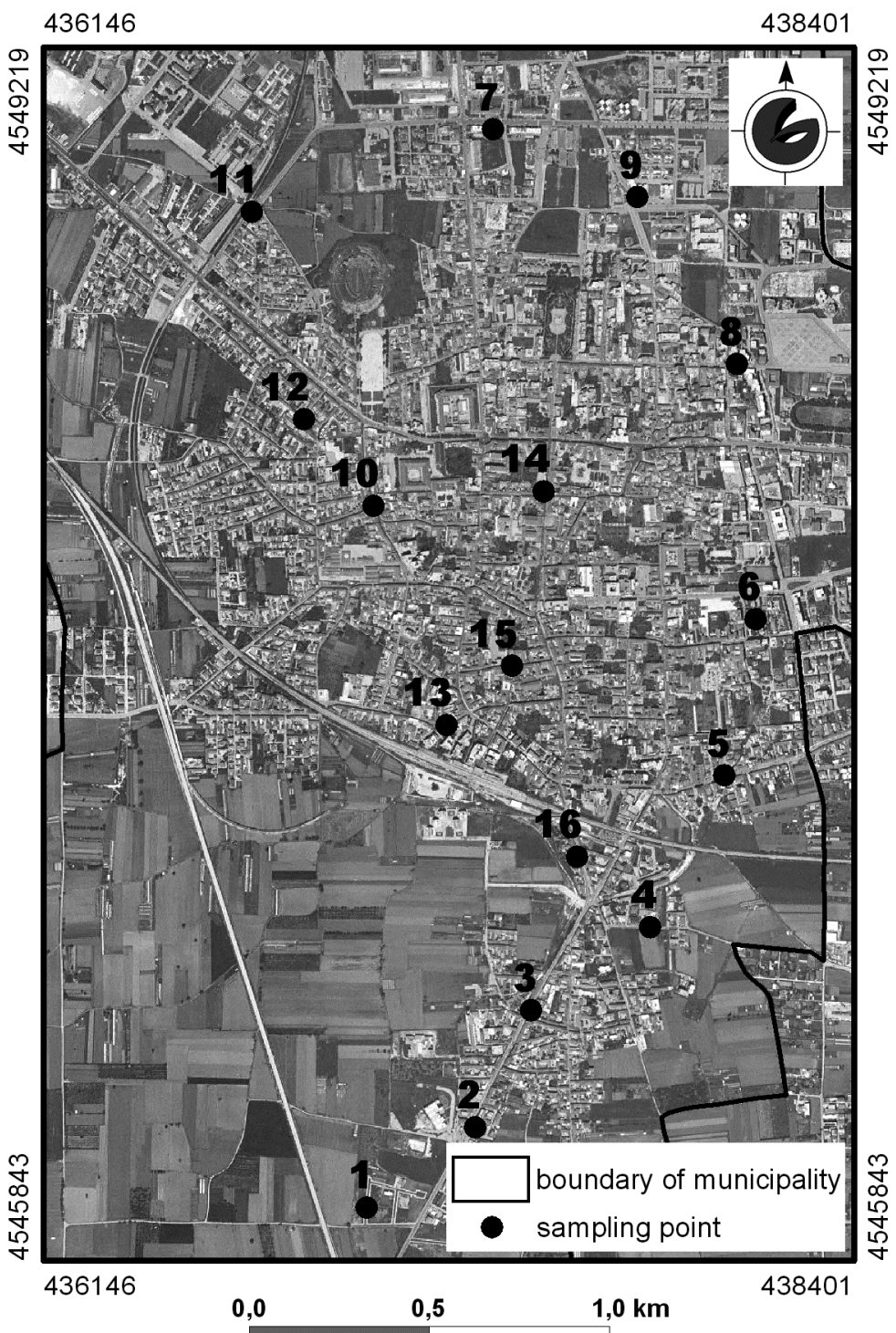

Figure 1: $\quad$ Map of the sampling points in S. Maria Capua Vetere.

\subsection{Statistical analysis}

Statistical analysis was carried out using the statistical software package Statistica 7 of StatSoft. 
Table 1: Average BTEX concentrations $\left(\mu \mathrm{g} \mathrm{m}^{-3}\right)$ recorded in 16 sampling sites in S. Maria Capua Vetere during 2006, 10 monitoring campaigns; standard deviations (\%) in parenthesis.

\begin{tabular}{|c|c|c|c|c|c|}
\hline site & benzene & toluene & ethylbenzene & $(\mathrm{m}+\mathrm{p})$-xylene & o-xylene \\
\hline 1 & $\begin{array}{l}3.8 \\
(35)\end{array}$ & $\begin{array}{c}12 \\
(48)\end{array}$ & $\begin{array}{l}2.3 \\
(48)\end{array}$ & $\begin{array}{c}5.4 \\
(50)\end{array}$ & $\begin{array}{c}2.6 \\
(50)\end{array}$ \\
\hline 2 & $\begin{array}{c}4.7 \\
(32)\end{array}$ & $\begin{array}{l}15.7 \\
(34)\end{array}$ & $\begin{array}{c}3.1 \\
(39)\end{array}$ & $\begin{array}{c}8.3 \\
(59)\end{array}$ & $\begin{array}{c}3.8 \\
(42)\end{array}$ \\
\hline 3 & $\begin{array}{c}7.5 \\
(25)\end{array}$ & $\begin{array}{l}29.5 \\
(40)\end{array}$ & $\begin{array}{c}6.6 \\
(50)\end{array}$ & $\begin{array}{l}18.5 \\
(70)\end{array}$ & $\begin{array}{c}8 \\
(43)\end{array}$ \\
\hline 4 & $\begin{array}{c}5.9 \\
(34)\end{array}$ & $\begin{array}{l}15.5 \\
(36)\end{array}$ & $\begin{array}{c}3.5 \\
(37)\end{array}$ & $\begin{array}{l}9.3 \\
(54)\end{array}$ & $\begin{array}{l}4.5 \\
(38)\end{array}$ \\
\hline 5 & $\begin{array}{l}11.4 \\
(32)\end{array}$ & $\begin{array}{l}34.6 \\
(30)\end{array}$ & $\begin{array}{l}7.6 \\
(33) \\
\end{array}$ & $\begin{array}{l}21.2 \\
(49)\end{array}$ & $\begin{array}{l}10.3 \\
(30)\end{array}$ \\
\hline 6 & $\begin{array}{l}4.0 \\
(33)\end{array}$ & $\begin{array}{l}12.6 \\
(37)\end{array}$ & $\begin{array}{l}2.6 \\
(46)\end{array}$ & $\begin{array}{l}6.5 \\
(62)\end{array}$ & $\begin{array}{c}3.2 \\
(38)\end{array}$ \\
\hline 7 & $\begin{array}{l}5.3 \\
(28)\end{array}$ & $\begin{array}{l}21.0 \\
(76)\end{array}$ & $\begin{array}{l}3.5 \\
(34)\end{array}$ & $\begin{array}{c}9.0 \\
(40)\end{array}$ & $\begin{array}{l}4.6 \\
(41)\end{array}$ \\
\hline 8 & $\begin{array}{c}5.1 \\
(31)\end{array}$ & $\begin{array}{l}14.3 \\
(34)\end{array}$ & $\begin{array}{c}3.2 \\
(41)\end{array}$ & $\begin{array}{c}8.8 \\
(55)\end{array}$ & $\begin{array}{c}4.2 \\
(31)\end{array}$ \\
\hline 9 & $\begin{array}{l}4.3 \\
(33)\end{array}$ & $\begin{array}{l}29.8 \\
(50)\end{array}$ & $\begin{array}{c}3.2 \\
(44)\end{array}$ & $\begin{array}{c}8.4 \\
(55)\end{array}$ & $\begin{array}{c}3.7 \\
(.35)\end{array}$ \\
\hline 10 & $\begin{array}{l}6.5 \\
(25)\end{array}$ & $\begin{array}{l}21.2 \\
(37)\end{array}$ & $\begin{array}{l}4.7 \\
(34)\end{array}$ & $\begin{array}{l}11.5 \\
(33)\end{array}$ & $\begin{array}{c}6.5 \\
(40)\end{array}$ \\
\hline 11 & $\begin{array}{c}8.5 \\
(21)\end{array}$ & $\begin{array}{l}25.3 \\
(23)\end{array}$ & $\begin{array}{c}5.1 \\
(43)\end{array}$ & $\begin{array}{l}13.1 \\
(64)\end{array}$ & $\begin{array}{c}6.6 \\
(55)\end{array}$ \\
\hline 12 & $\begin{array}{c}5.2 \\
(60)\end{array}$ & $\begin{array}{l}21.2 \\
(67)\end{array}$ & $\begin{array}{c}4.7 \\
(70)\end{array}$ & $\begin{array}{l}12.2 \\
(80)\end{array}$ & $\begin{array}{c}6.2 \\
(49)\end{array}$ \\
\hline 13 & $\begin{array}{c}7.3 \\
(30)\end{array}$ & $\begin{array}{l}24.5 \\
\text { (43) }\end{array}$ & $\begin{array}{c}4.9 \\
(49)\end{array}$ & $\begin{array}{l}13.6 \\
(74)\end{array}$ & $\begin{array}{c}6.3 \\
(49)\end{array}$ \\
\hline 14 & $\begin{array}{l}10.5 \\
(22)\end{array}$ & $\begin{array}{l}34.6 \\
(23)\end{array}$ & $\begin{array}{l}7.6 \\
(26)\end{array}$ & $\begin{array}{l}20.0 \\
(35)\end{array}$ & $\begin{array}{l}10.6 \\
(30)\end{array}$ \\
\hline 15 & $\begin{array}{c}6.4 \\
(33)\end{array}$ & $\begin{array}{l}19.7 \\
(47)\end{array}$ & $\begin{array}{c}4.4 \\
(48)\end{array}$ & $\begin{array}{l}10.1 \\
(40)\end{array}$ & $\begin{array}{l}5.7 \\
(51)\end{array}$ \\
\hline 16 & $\begin{array}{c}6.0 \\
(2.4)\end{array}$ & $\begin{array}{c}20.4 \\
(10.5)\end{array}$ & $\begin{array}{c}4.0 \\
(2.0)\end{array}$ & $\begin{array}{c}9.7 \\
(5.2)\end{array}$ & $\begin{array}{c}5.3 \\
(3.0)\end{array}$ \\
\hline $\begin{array}{l}\text { All } \\
\text { the } \\
\text { sites }\end{array}$ & $\begin{array}{l}6.5 \\
(31)\end{array}$ & $\begin{array}{l}22.4 \\
(42)\end{array}$ & $\begin{array}{l}4.0 \\
(42)\end{array}$ & $\begin{array}{c}9.7 \\
(55)\end{array}$ & $\begin{array}{c}5.3 \\
(42)\end{array}$ \\
\hline
\end{tabular}




\section{Results and discussion}

\subsection{Concentrations in the sampling sites}

Although this survey was carried out in a medium-size city, the average concentrations were relatively high in reference to the limit values required by the European Union. For example, we recorded an average value for benzene, computed using data from all the sites, of $6.5 \mu \mathrm{g} \mathrm{m}^{-3}$, value higher than the limit value of $5 \mu \mathrm{g} \mathrm{m}^{-3}$ fixed by the EU. Table 1 summarizes the average BTEX concentrations recorded in S. Maria Capua Vetere during 2006. As can be seen, there is a marked difference from site to site, in spite of the relatively small size of the city: in the sites 5 and 14 we observed BTEX concentrations more than twice higher than the value observed in the site 1 . This last site was in a street with low traffic intensity in a suburban area with no industrial activity in its immediate surroundings. Therefore, this sampling site was a good indicator of the background pollution level in the area. The higher pollutant concentrations were measured in sites 5 and 14. These were located in streets that had moderately intense traffic, but were relatively narrow and bordered by high buildings on either side. The canyon effect seems the dominant element in determining high pollution levels.

\subsection{Statistical analysis}

Statistical analyses by means of one-way ANOVA, followed by Tukey's test [8], of the 24-hour average concentrations recorded in each site showed that the differences among sites (discussed in the previous section) are statistically significant. For many couples of sites the $\mathrm{P}$ values were $<0.01$. As regard the correlation among the BTEX concentrations, statistical analysis showed a strong positive correlation (Table 2).

Table 2: Correlation coefficients between 24-hour average BTEX concentrations recorded during 2006 in the city of S. Maria Capua Vetere.

\begin{tabular}{lccccc}
\hline & Benzene & Toluene & Ethylbenzene & $(\mathrm{m}+\mathrm{p})$-Xylene & o-Xylene \\
\hline Benzene & 1 & 0.76 & 0.90 & 0.83 & 0.88 \\
Toluene & & 1 & 0.81 & 0.71 & 0.77 \\
Ethylbenzene & & & 1 & 0.91 & 0.97 \\
$(\mathrm{~m}+\mathrm{p})-X y l e n e$ & & & & 1 & 0.83 \\
o-Xylene & & & & & 1 \\
\hline
\end{tabular}

This suggests that in the city there is one major source of BTEX, probably the vehicular traffic. However, the correlation coefficients obtained in the present study are lower than the coefficients reported by us [9] and those for similar works $[10,11]$. It is interesting to note that the lowest coefficients were observed 
for toluene versus all the other pollutants. Comparison of correlation matrixes, computed excluding in turn the contribute of each site, showed that the sites 7,9 and 11, all located in the north of the city (Figure 1), contributed markedly to lower the correlation coefficients. When these were excluded from the analysis, a marked increment of the coefficient values was observed. Table 3 reports the correlation matrix computed without the contribution of these sites.

Table 3: Correlation coefficients between the 24-hour average BTEX concentrations calculated without the data recorded in sampling sites 7,9 and 11 .

\begin{tabular}{lccccc}
\hline & Benzene & Toluene & Ethylbenzene & $(\mathrm{m}+\mathrm{p})$-Xylene & o-Xylene \\
\hline Benzene & 1 & 0.90 & 0.91 & 0.84 & 0.90 \\
Toluene & & 1 & 0.92 & 0.82 & 0.90 \\
Ethylbenzene & & & 1 & 0.91 & 0.97 \\
$(\mathrm{~m}+\mathrm{p})-$ Xylene & & & & 1 & 0.84 \\
o-Xylene & & & & & 1 \\
\hline
\end{tabular}

Coherently with this result, a coefficient matrix computed using only the data from the sites 7,9 and 11 has low coefficients, particularly for the toluene terms (Table 4). This result is a clear indication of toluene emission not only from vehicular traffic but also from stationary source at the sites 7, 9 and 11 . Assuming that the ratio between toluene and benzene concentrations in the other sites reflects emission from traffic we computed that about the $40 \%$ of toluene in the atmosphere at sites 7,9 and 11 was from the stationary source.

Table 4: Correlation coefficients between the 24-hours average BTEX concentration calculated using only the data recorded in the sampling sites 7,9 and 11 .

\begin{tabular}{lccccc}
\hline & Benzene & Toluene & Ethylbenzene & $(\mathrm{m}+\mathrm{p})$-Xylene & o-Xylene \\
\hline Benzene & 1 & 0.27 & 0.81 & 0.73 & 0.74 \\
Toluene & & 1 & 0.46 & 0.37 & 0.36 \\
Ethylbenzene & & & 1 & 0.90 & 0.95 \\
$(\mathrm{~m}+\mathrm{p})-X y l e n e$ & & & & 1 & 0.82 \\
o-Xylene & & & & & 1 \\
\hline
\end{tabular}

Figure 2 shows the concentration gradient maps for benzene and toluene as obtained by GIS software. In agreement with the results of the coefficient matrix, there are significant differences between the two maps. In the top of the benzene map we observe lower concentration, while in the toluene map we observe a relative maximum. 

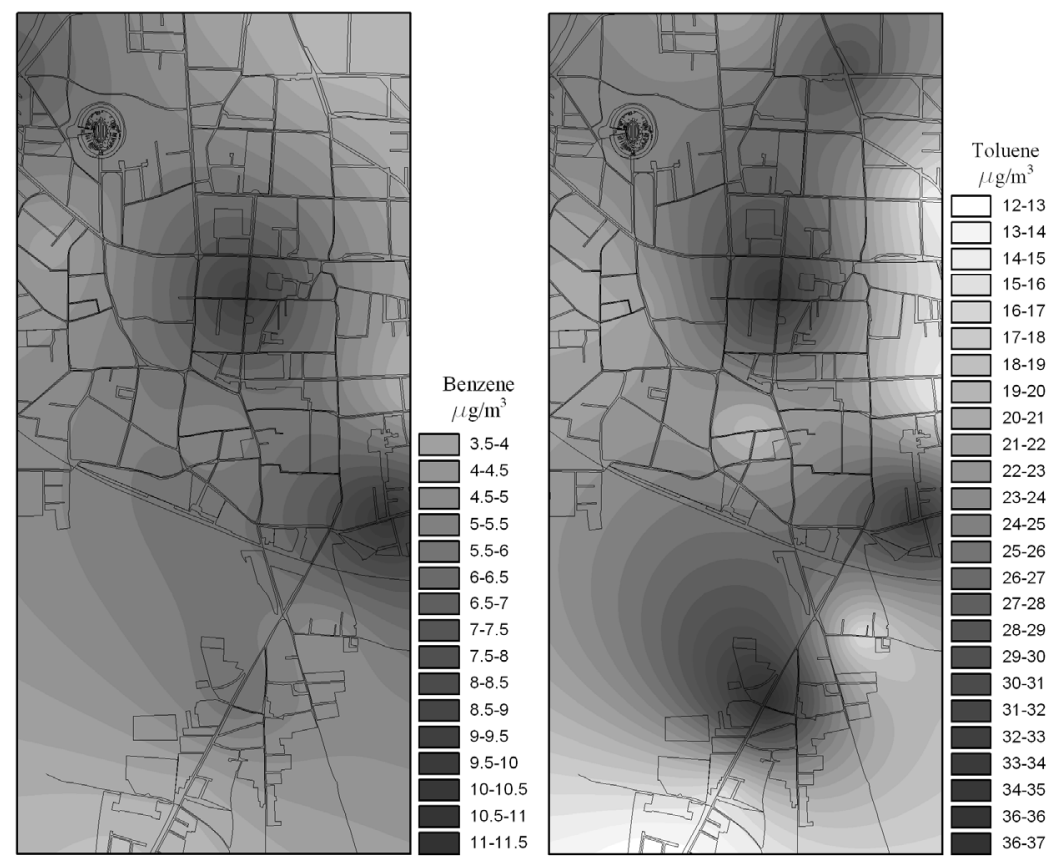

Figure 2: Benzene (left) and toluene (right) concentration distributions in S. Maria Capua Vetere, as obtained by GIS software.

\section{Conclusion}

The results presented here show that air pollution analysis by passive samplers distributed in the studied area combined with appropriate statistical treatment and GIS elaboration of the data, is a powerful technique for environmental control. Not only it provides detailed information on the pollution levels throughout the territory, but also permits to identify minor stationary sources.

\section{References}

[1] Senfeld, J.H., Pandis, S.N. Atmospheric Chemistry and Physics, John Wiley \& Sons., New York, 1998.

[2] Ruchirawat, M., Navasumrit, P., Settachan, D., Tubtaviroon J., Buthbumrung, N., Sharma, S. Measurement of genotoxic air pollutant exposures in street vendors and school children in and near Bangkok. Toxicol. Appl. Pharmacol., 206, pp. 207-214, 2005. 
[3] Kerbachi, R., Boughedaoui, M., Bounoua, L., Keddam, M. Ambient air pollution by aromatic hydrocarbons in Algiers. Atmospheric Environment, 40, pp. 3995-4003, 2006.

[4] Lin, T., Sree, U., Tseng, S., Chiu, K.H., Wu, C., Lo, J. Volatile organic compound concentrations in ambient air of Kaohsiung petroleum refinery in Taiwan. Atmospheric Environment, 38, pp. 4111-4122, 2004.

[5] Srivastava, A. Source apportionment of ambient VOCS in Mumbai city. Atmospheric Environment, 38, pp. 6829-6843, 2004.

[6] Siegl, W.O., Mccabe R.W., Chun W., Kaiser E.W., Perry J., Henig Y. I., Trinker F. H., Anderson R. W. Speciated hydrocarbon emissions from the combustion of single component fuels. I: Effect of fuel structure. Journal of the Air and Waste Management Association, 42, pp. 912-920, 1992.

[7] McGinty, R.P., Dent N. P. A review of the effect of petrol composition on unregulated motor vehicle emissions with particular emphasis on noncatalyst vehicles. Environmental Technology, 16, pp. 603-623, 1995.

[8] Foweler, J., Cohem, L. Practical statistics for field biology, John Wiley \& Sons., New York, 1990.

[9] Iovino, P., Salvestrini, S., Capasso, S. Background atmospheric levels of BTEX in a medium-sized city and surrounding area in Southern Italy. Air Pollution XIV, C.A. Breddia Ed., pp. 611- 618, 2006.

[10] Fernandez-Martinez G., Lopez-Mahia P., Muniategui-Lorenzo S., PradaRodriguez D., Fernandez-Fernandez E. Measurement of volatile organic compounds in urban air of la Coruña, Spain. Water, air and soil pollution, 129, pp. 267-288, 2001.

[11] Hansen, A.B., Palmgren, F. VOC air pollutants in Copenhagen. Science of the Total Environment 189/190, pp. 451-457, 1996. 